\title{
Accessibility in designing centralised warehousing: case of health care logistics in Northern Finland
}

\begin{abstract}
Long distances and sparse service networks set challenging conditions for material logistics in health care. Globally, health care organisations have been making structural changes towards centralised warehousing and deliveries. In Northern Finland, material logistics of the public health care system rely mainly on numerous separate order and delivery systems, although logistics needs, ordering and stock in different health care facilities correspond to each other. As centralised logistics in orders and deliveries may lead to remarkable savings, pressure for centralised management is high. This paper analyses how effectively a potential centralised warehousing system can be organised based on its spatial components. These include optimal location of one or more warehouses, delivery network coverage and efficiency of routes, as well as accessibility of health centres and hospitals. The geographic information systems (GIS) -based accessibility analytical framework described in this study applies vehicle routing and heuristic computations to locationallocation of warehouses to potential sites by optimising transport cost with a constraint to provide service to at least $90 \%$ of delivery demand. The spatial data include the road network, health care facility locations with rough estimates of freight demand nodes and potential locations of warehouse facilities. The main findings of the study show that majority of health centres and hospitals can be effectively reached by a delivery network based on one or two warehouses. Furthermore, the efficiency of the delivery network does not increase remarkably by increasing the number of warehouses, when measured as driving time.
\end{abstract}

Keywords: Accessibility, freight, health care, location-allocation, logistics, warehouse

\section{Introduction}

Healthcare systems in all parts of the world are under pressure to improve performance in service terms and in relation to cost efficiency. In addition to patient processes, these challenges also pertain to the various support activities such as materials management and logistics. Compared to industrial and retail organisations, the opportunities for logistics improvements have, however, received relatively little attention in the healthcare sector. There are unique features that affect the applicability of logistics knowledge from the industrial sector to healthcare (de Vries \& Huijsman, 2011), but evidence shows that logistics innovations can in fact offer significant potential for performance improvements also in healthcare (e.g. Jarrett, 1998).

Cost pressures have led healthcare organisations to consider structural changes for reducing costs while still gaining value (Kaplan \& Porter, 2011). Lower cost-structures and increasing service levels in healthcare are achieved in many cases by redesigning material logistics (Poulin, 2003), for instance by centralising warehouses (Kumar et al., 2008). Sometimes these reforms also aim at more comprehensive changes in healthcare supply chains in the manner of industry-led initiatives such as quick response (QR) or efficient consumer response (ECR) for instance (Landry \& Filippe, 2004).

Designing and analysing hub locations of freight and passengers have been on fields of academic studies for 30 years (Campbell \& O'Kelly, 2012) and a significant extent of research contributions have been provided by operations research, logistics, supply chain management, operations management, geography, network design, telecommunications, regional science and economics including interdisciplinary perspectives (see Farahani et al., 2013; Geoffrion \& Powers, 1995). A vast number of location-allocation models have been developed for different analytical needs, even though they share a common theoretical background (see Polo et al., 2015; Lei et al., 2016). The warehouse location optimisation problem as a spatial analysis is a subtype of graph-based facility location problems (Brahimi \& Khan, 2014; Rodrigue et al., 2013: 176-179, 306-317). Thus, the warehouse location problem can be scrutinised by simulated delivery routes (Bosona \& Gebresenbet, 2011; Prodhon \& Prins, 2014). Geographic information systems (GIS) are applied widely to solve spatial location problems (Miller \& Shaw, 2001; Tong \& Murray, 2012) having relevance also in the field of health care (Cromley \& McLafferty, 2011), and in the context of freight GIS offers an adaptive framework for spatial optimisation of delivery routes and location-allocation analysis of warehousing facilities (Bozkaya et al., 2010). 
In this paper we focus on logistics systems in public healthcare in Finland, especially in the northern part of the country. We are particularly interested in the opportunities for healthcare organisations to adopt centralised warehousing operations, a strategy that has generated considerable savings in logistics costs (e.g. Becker et al., 2016), reduction of environmental impacts (e.g. Kohn \& Brodin, 2008), and also service-level improvements (e.g. Abrahamsson et al., 2003) in various manufacturing and retail industry settings. Again, the sparse population and long distances create special challenges for the logistics management of healthcare organisations. In Northern Finland, 742,000 inhabitants live in the area of 172,600 $\mathrm{km}^{2}$. This results in a sparse population density of 4.3 inhabitants per $\mathrm{km}^{2}$, which corresponds, e.g. to Norrland in Sweden, British Columbia in Canada and North Dakota in the United States. The two largest cities, Oulu and Rovaniemi, comprise $39 \%$ of the population of the region. Distances between hospitals and health centres are long. The distance from the most remote health centre to the nearest hospital is $453 \mathrm{~km}$, and to the nearest university hospital $675 \mathrm{~km}$.

The analysis of the study considers locating centralised warehouse(s) within areas characterized by long distances and relatively low demand, by location-allocation applying optimal routes of delivery vehicles. The study aims also to disclose the relationships (trade-offs) between service accessibility and delivery costs by optimising the spatial components of the logistics delivery network. Methods of the study consist of vehicle routing problem-based location-allocation analysis implemented in GIS. The aim of the study is approached through two research questions. 1) How extensive must a delivery network be to produce adequate logistics services for healthcare in sparsely populated areas? 2) What is the most efficient spatial distribution of centralised warehouses with objectives to minimise the number of facilities opened and to minimise transport costs when the constraint is to provide service to at least $90 \%$ of delivery demand?

\section{Healthcare logistics and accessibility analysis}

A basic definition describes logistics as the task of coordinating material flow and information flow across the supply chain (Harrison \& van Hoek, 2005). Logistics includes activities connected to the transformation and circulation of goods, such as the material supply of production, the core distribution and transport function, wholesale, retail as well as the related information flows (Handfield \& Nichols, 1999). The mission of logistics management is to plan and coordinate all those activities necessary to achieve desired levels of delivered service and quality at the lowest possible cost (Christopher, 1998).

In the healthcare context logistics research is generally divided into two genres by the unit of analysis. Most of the research focuses on patient flows and care processes (de Vries \& Hujisman, 2011) while research on supporting material flows has been quite limited (Olsson et al., 2014; Vissers \& Beech, 2005: 26). This has been attributed to the complex nature of health care supply chains and merely a supporting role of logistics in health services (Beier, 1995; Abjulsalam et al., 2015; Jarrett, 1998). However, the importance of material flows in healthcare systems is gradually becoming recognised and the potential improvements that can be accomplished are also getting attention in the academic research of logistics and healthcare management (e.g. Jarrett, 1998; Landry \& Philippe, 2004; Kumar et al., 2008).

Optimisation is at the heart of designing efficient logistics systems (Geoffrion \& Powers, 1995; Graves et al., 2000). In a healthcare logistics context, for instance, optimisation can mean that facility locations are designed in a manner that total logistics costs of material deliveries to hospitals and other healthcare units are minimised at required service levels (Jarrett, 1998). Increasing the number of service points in a distribution network generally leads to quicker responses and therefore a better service level. This raises customer satisfaction, but on the other hand increases total logistics costs such as inventory costs, transportation costs and facility costs (Heizer et al., 2017:497; Croxton \& Zinn, 2005.) In logistics decision-making this kind of trade-off analysis is embodied in the total cost concept (Ballou, 2004:44), representing the cost patterns of various activities with characteristics that frequently set them in conflict with one another. However, the trade-off analysis also applies to the relationship between service level and logistics costs (e.g. Christopher, 1998:51). A critical point to consider is that the costs normally grow exponentially as the service level increases in a linear manner.

The reasonable optimum between costs and service can be found by focusing on the core dimensions of transport geography: networks, nodes/locations and flows (Hesse \& Rodrigue, 2004). Transport geographic accessibility analyses include a wide set of methods analysis and optimisation methods (Páez et al., 2012) 
which are applicable to analysing and solving location-allocation problems of the health care sector (Coffee et al., 2012; McGrail \& Humphreys, 2014; Mestre et al., 2015). However, analysis considering freight delivery by land transports and optimisation of deliveries is more infrequent within transport geography (see Rodrigue, 2006), and particularly in the case of low and dispersed demand. Geographic optimisation of freight deliveries is applied to logistics occasionally (Melo, 2009), and recent examples can be found from the food distribution industry at the scale of a city region (Gebresenbet et al., 2011), in state-level food transports (Bosona \& Gebresenbet, 2011) and from intermodal routing of container freight at a regional scale (Zhang \& Pel, 2016). In this context, the GIS framework is a powerful tool for implementing locationallocation analyses with spatial data (Miller \& Shaw, 2001; Rodrigue et al., 2013: 317-322).

A large variety of optimisation methods are developed to serve strategic, tactical, and operational needs of freight transport planning. Operational planning is performed on a detailed level and dynamic environment, and tactical planning focuses on developing the performance of the existing system. This paper considers a level of strategic planning covering a wider time horizon, includes larger investments and determines development policies and operation strategies, and thus also develops the physical distribution network and location of main facilities (see Crainic, 1997). Three main types of facility location analysis are defined as 1) continuous location models having a solution space, where facilities could be located on every planar point; 2) network location models applying least-cost path distances and nodes representing demand points and potential facility sites, like in classical p-median allocation, and 3) mixed integer-programming models that are discrete techniques, but applicable to a set of given potential facility sites and given distances metrics (Klose \& Drexl, 2005). Mixed integer programming analyses can be again classified as single- or multi-stage models in relation to hierarchies of facilities, and again, methods can be tailored to consider also capacity of depots or their ability to manage different types of products. Different model types are available for including temporal dynamics or considering a static setting. However, when location and routing decisions are strongly interrelated, as in this paper, 'routing location models' related to both the classical locationallocation problem and the vehicle routing problem can be applied (Nagy \& Salhi, 2007). Furthermore, the complicated optimisation task is simplified in this study, by hard constrains in relation to transport capacity, transport time, cost-efficiency and number of potential sites.

\section{Health care logistics and transports in the context of Northern Finland}

The study case and its context were researched through interviews and a compilation of key figures to recognise and parameterise the demands of healthcare logistics (see preliminary studies Kotavaara et al., 2015; Pohjosenperä et al., 2016). Pre-studies and interview data consider material logistics of the most essential public health care organisations in the case area. Data was collected in three stages. Background knowledge of the organisations was explored firstly in 2012 through a pre-study of the university hospital district of Northern Ostrobothnia including field work. Secondly, discussions with the hospital districts in 2013-2014 broadened the view. Thirdly, more detailed information was collected through interviews (5) and by group discussions between April and October 2015. Interviews were semi-structural and some questions were given to the interviewees beforehand, to get the key figures to form estimations of the volumes of the deliveries with needed accuracy. The interviewees were persons responsible for material logistics, warehousing and/or purchasing functions in their hospital district. The interviews cover three hospital districts in the case area, Northern Ostrobothnia, Lapland, and Länsi-Pohja, and also two comparative hospital districts in Norrbotten (Sweden) and Satakunta. Furthermore, to evaluate and develop further the preliminary GIS-model of the study, two group discussions were arranged in May 2015 with health care logistics professionals from Lapland hospital district, Northern Ostrobothnia hospital district, the City of Oulu and the consulting company NHG.

In the case region, hospitals and health centres have alternating needs for freight volumes and frequencies of the deliveries. Roughly, health centres need to be served two times a week, whereas primary-level health care facilities and major health centres need to have weekly delivery frequency. However, hospitals and specialised health care require several deliveries during a week. Shipped materials are care items, instruments such as knives, medicine, food, laundry, laboratory samples, assistive devices - in other words all the materials that are needed in providing healthcare services. Despite partially centralised procurement, hospitals and health centres in the case area manage these material flows independently. 
In the delivery network there is time required for driving and for unloading and loading procedures. At average health centres this takes approximately 10 minutes. In the comparative cases in Norrbotten and Satakunta the centralised warehouse delivers also value adding services such as order-replenishment, in which case service time related to unloading of freight and shelving may increase significantly. These services can also be provided by the care personnel or outsourced to a third party.

The healthcare units are divided into three groups: health centres, minor and major district hospitals and university hospital. Health centres $(n=92)$ are situated in almost all municipalities and they take care of the basic health services (see Figure 1). District hospitals $(n=5)$ in the area address special health care needs and are located in the cities of Rovaniemi, Kemi, Kajaani, Kokkola and Oulainen. The major hospital in Oulu is the university hospital that has the main responsibility for providing the most specialised health care. The quantities of material delivered to health centres vary between $0.7 \mathrm{~m}^{3}$ and $1.7 \mathrm{~m}^{3}$ per week, without laundry, food and medicines (Table 1). Minor district hospitals receive $7.5 \mathrm{~m}^{3}$ of materials weekly, whereas the number for major district hospitals is $30 \mathrm{~m}^{3}$. The university hospital receives $264 \mathrm{~m}^{3}$ per week. The geographic distribution of indicative freight distribution of health care is presented in Figure 1.

Table 1. Estimated volumes $\left(\mathrm{m}^{3}\right)$ of incoming freight (no laundry, food and medicines) per week to different size health care units (health centre, minor hospital, major hospital) in northern context.

\begin{tabular}{|c|c|c|c|}
\hline $\begin{array}{l}\text { Northern } \\
\text { Ostrobothnia hospital } \\
\text { district, Finland } \\
\text { (Oulu) }\end{array}$ & $\begin{array}{l}\text { Lapland } \\
\text { hospital district, } \\
\text { Finland } \\
\text { (Rovaniemi) }\end{array}$ & $\begin{array}{l}\text { Länsi-Pohja } \\
\text { hospital district, } \\
\text { Finland } \\
\text { (Kemi) }\end{array}$ & $\begin{array}{l}\text { Indicative } \\
\text { nodal weight } \\
\text { for analysis }\end{array}$ \\
\hline
\end{tabular}

\begin{tabular}{lcccc}
\hline $\begin{array}{l}\text { University } \\
\text { hospital }\end{array}$ & $264 / 330^{1}$ & - & - & 264 \\
$\begin{array}{l}\text { District } \\
\text { hospitals } \\
\text { (minor and }\end{array}$ & $7.5 / 11$ & 30 & $>30$ & $7.5 / 30$ \\
major) & & & & \\
Health centres & 1.6 & $1.4 / 0.7^{2}$ & 1.7 & 1.5 \\
\hline
\end{tabular}

1 Incoming to hospital / incoming including deliveries to other units

2 Health centre / other distribution target

3 Reference case 


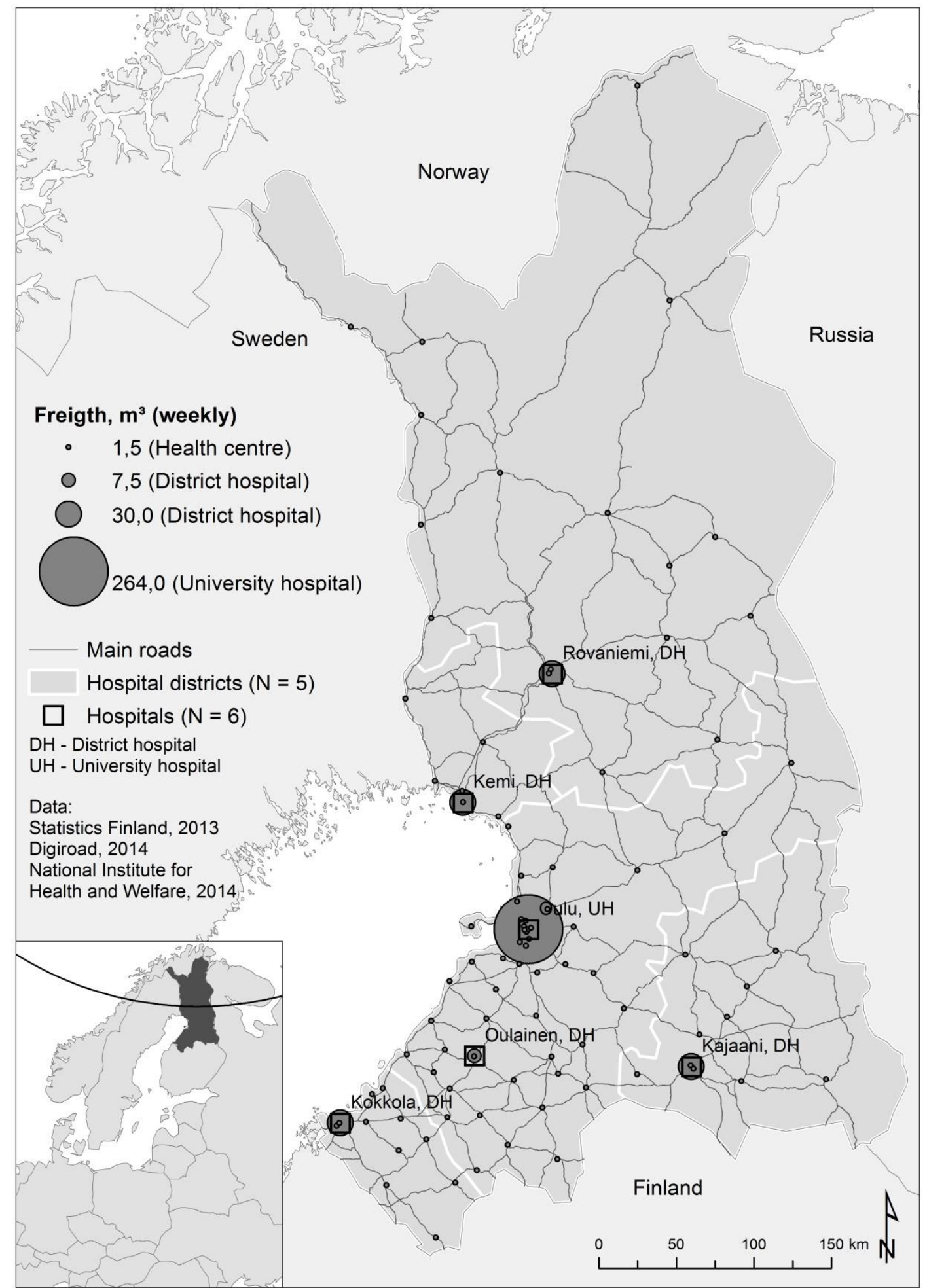

Figure 1. Geographic distribution of estimated freight volumes of hospitals and health centres, and potential warehouse locations, i.e. main hospital cities of the case region.

\section{Methods and data}

Analysis aims to find a solution for locating one warehouse or a combination of a few warehouses to a limited number of potential sites by tour-based location-allocation. Efficiency of sites in freight delivery accessibility is evaluated on the basis of optimised delivery routes, sum of delivered freight and transport time accumulation (see e.g. Bosona \& Gebresenbet, 2011). In the study, traditional location-allocation 
analysis modelling accessibility of customers with back-and-forth travels (see e.g. Luo, 2014) was updated to apply tour shapes delivery routes. Analyses are implemented in a GIS framework by using Python 3.0 scripts, vehicle routing problem analysis ESRI (2012), Finnish Transport Agency Digiroad data and locational freight delivery demand data (Table 1). The analysis aims to find a suitable compromise between reach of the delivery network, transport costs and number of warehouses with realistic route generation. Delivery routes are optimised with heuristic computation by minimising tour time when delivered freight per time and share of delivered freight are the key constraints.

\subsection{GIS road network data and health care facilities}

GIS road network data consists of all regularly used roads including regional and local main streets, collector and feeder streets (Finnish Transport Agency, 2014), and data enabling estimation of travel speed as impedance to transport (see Kotavaara et al., 2011). Travel speeds were estimated for a delivery van or smaller truck, and the maximum speed limited to $80 \mathrm{~km} / \mathrm{h}$. In Northern Finland the speed limit-based travel time estimates are accurate in typical circumstances, due to the minor effect of congestion in the area (compare to Yiannakoulias et al., 2013; Tenkanen et al., 2016). However, travel times in built-up areas are increased by $25 \%$. Road ferry connections were included in the digital road network data, estimating a speed of $10 \mathrm{~km} / \mathrm{h}$ for cable ferries and $20 \mathrm{~km} / \mathrm{h}$ for larger ferries. Winter conditions such as cold weather, snow and darkness in Northern Finland present certain challenges for road transport. However, people and organisations in the region are fairly accustomed to these conditions and stable winter conditions are not considered to have a notable effect on transport driving speeds (see Ahlqvist et al., 2014:34). Driving speeds in the area are limited during the winter (mainly $100 \mathrm{~km} / \mathrm{h}$ to $80 \mathrm{~km} / \mathrm{h}$ ), whereas heavy vehicle speed is limited to $80 \mathrm{~km} / \mathrm{h}$ throughout the year. Exceptional conditions like snow storms and floods create more challenges, but these are mainly rare force majeure situations.

Basic health care and hospital facilities were positioned by geocoding street addresses of facilities in relation to GIS road network data. Finnish health care facilities data are maintained by the National Institute for Health and Welfare. In Northern Finland there were six hospitals (being active in special health care, advanced surgery and births) and 92 health centres at the end of year 2014. Health care facility data is manually validated to preclude occurrence of errors.

\subsection{Delivery route generation and assessing accessibility of warehouse sites}

Location-allocation of warehouses is based on optimised tours of delivery vehicles. Key attributes in allocation are the accumulated sum of delivered freight $(v)$ measured in cubic metres $\left(\mathrm{m}^{3}\right)$ and time $(\mathrm{h})$ consumed during transports, loading and unloading. Each delivery route has a start and end point at the same warehouse site and the tour of delivery route is optimised to reach freight demand nodes efficiently together with other routes. In route optimisation the aim is to minimise transport cost as time (h) and maximise the sum of accessed nodal weights of freight delivery demand $\left(\mathrm{m}^{3}\right)$. Computing in the GIS environment is executed with Python 3.0 script.

In route solving, the study applies the ArcGIS vehicle route problem (VRP) tool designed for routing several vehicles accessing several destinations with differing weights. More specifically expressed, the analysis for VRP calls the solution for the determination of a set of routes, each performed by a single vehicle which starts and ends at its own depot, fulfilling all customer requirements and minimising transport costs (see Baldacci et al., 2010). Analogically, VRP is a superset of the classical traveling salesman problem, which is a combinatorial problem. Consequently, there is no applicable method to find the optimal solution with certainty, and heuristic algorithms are needed to find suitable solutions in a reasonable time. ESRI (2012) does not share the VRP functions openly, but reports that the ArcGIS VRP solver operates on the basis of an origin-destination matrix of fastest routes and applies further developed tabu search metaheuristics.

All potential warehouse location combinations are considered with the presumption that one or a few warehouse(s) are located within some of the six major hospitals in the study area. Number (n) of different potential locational settings of one or more warehouses to $(S)$ sites is,

$$
n=2^{S}-1
$$

resulting in 63 combinations, when at least one warehouse will be located. In each of these cases, delivery routes are optimised by VRP and efficiency of routes is then assessed by driving time $\left(H_{n}\right)$ accumulation and 
by successful freight delivery $V_{n}$ accumulation. Thus, the freight accessibility efficiency $(E)$ for each warehouse setting accessibility can be written

$$
\begin{gathered}
E=\frac{V_{n}}{H_{n}} \\
V_{n}=\sum_{i=1}^{n} \sum_{j=1}^{o} \sum_{k=1}^{p} V_{k} \mid, V_{k} \subset V \\
H_{n}=\sum_{i=1}^{n} \sum_{j=1}^{o} h_{j}
\end{gathered}
$$

where: warehouse sites are from $i$ to $n$; delivery routes are from $j$ to $o$ for each warehouse; number of deliveries in each route are from $k$ to $p ; V_{k}$ is volume of successful deliveries $\left(\mathrm{m}^{3}\right)$ by each warehouse setting, being member of all potential deliveries in set $V$ and $h_{j}$ is driving time of each delivery route; and $H_{n}$ sum of times in the route setting.

To establish an operable and illustrative service network, five hard constraints were applied in the computation. 1) Maximum time for each route was $9 \mathrm{~h}$ (on the basis maximum allowed driving time in EU and Finnish legislation), which includes driving time and service time of 10 minutes in the beginning and for every stop on a route. 2) Maximum load was restricted to $60 \mathrm{~m}^{3} .3$ ) Maximum number of delivery routes for each warehouse was set to 17 , as it was found to be the upper limit for tours with reasonable cost-efficiency. 4) Minimum cost-effectiveness of each route was set to be $0.5 \mathrm{~m}^{3} / \mathrm{h}$ (which corresponds to a daily $4.5 \mathrm{~m}^{3}$ delivery rate). Routes for each set of warehouse sites were optimised by heuristic iterative computation, aiming to maximise the cost effectiveness of the delivery network, until 5) the minimum delivery share (90\% of all potential deliveries) was reached.

Heuristic iteration targeting to optimise delivery efficiency $\left(E_{j}\right)$

$$
E_{j}=\frac{\sum_{k=1}^{p} V_{k}}{h_{j}}
$$

for each route was executed by generating the most extensive delivery network possible. Routes of this network were rationalised by stepwise computation, wherein inefficient routes were shortened in each step. Greedy heuristics was applied to implement stepwise enhancements iteratively within a reasonable time. For correcting maximum travel cost $\mathrm{H}_{1}$ of each route in the next computation sequence, term $\left(\mathrm{h}_{\Delta}\right)$ was applied. The applied function may be written

$$
\begin{gathered}
H_{l+1}=H_{l}-h_{\Delta} \mid, \text { wherein } \\
h_{\Delta}=\left(1-\frac{v_{T} / h_{T}}{\left(\sum_{k=1}^{p} V_{k}\right) / h_{j}}\right) \times h_{j} / 2
\end{gathered}
$$

wherein the ratio between target delivery efficiency $v_{T} / h_{T}$ and observed delivery efficiency indicates the needed correction. As several routes were adjusted during the same sequence, and some of the freight delivery demand nodes were potentially released for rerouting in next routing step, half of the minimum computational inefficiency was applied to adjust the route in the next step. In other words, routes with weak efficiency were strongly readjusted and routes with high but not satisfactory efficiency were carefully readjusted and some surplus capacity was allocated to the next iteration turn. 


\section{Results}

The location-allocation analysis seeks to define the most efficient spatial distribution of centralised warehouses by optimised delivery routes in which health service sites are assigned as customers. The aim is to minimise transport costs $\left(\boldsymbol{H}_{\boldsymbol{n}}\right)$ and the number of facilities $(\boldsymbol{n})$, when key the constraints are to provide service to at least $90 \%$ of combined delivery demand $\left(\boldsymbol{V}_{\boldsymbol{n}}\right)$ and to keep the ratio between transport time and freight delivery accumulation $\left(E_{j}\right)$ high enough. Thus, the trade-off view in finding balance between transport costs and coverage of delivery network is included in the analysis. The key finding is that the considerably low (weekly $529.5 \mathrm{~m}^{3}$ ) and dispersed (see Figure 1) demand of freight deliveries can be reached and satisfied by a centralised warehousing system with decent efficiency, as the great majority of freight delivery demand (95.2\%) in the study area can be assigned efficiently to tours operated from one warehouse. The sum of transport costs is equal to 71.7 hours of driving time (Table 2).

Table 2. Number of allocated warehouses and metrics related to the most efficient delivery networks.

\begin{tabular}{|c|c|c|c|c|c|c|c|c|c|}
\hline \multirow{2}{*}{$\begin{array}{c}\text { Warehouses } \\
\boldsymbol{n}(\mathbf{N})\end{array}$} & \multirow{2}{*}{$\begin{array}{c}\text { Cost } \\
\boldsymbol{H}_{\boldsymbol{n}}(\mathbf{h})\end{array}$} & \multirow{2}{*}{$\begin{array}{c}\text { Deliveries } \\
\mathbf{V}_{\mathbf{n}}\left(\mathbf{m}^{\mathbf{3}} /(\mathbf{\%}) / \mathbf{N}\right)\end{array}$} & \multirow{2}{*}{$\begin{array}{c}\text { Efficiency } \\
\mathbf{E}_{\mathbf{j}}\left(\mathbf{m}^{\mathbf{3}} \mathbf{h}\right)\end{array}$} & \multicolumn{5}{|c|}{ Potential warehouse sites } \\
\hline 1 & 71.7 & $504.0 / 95.2 / 85$ & 7.03 & 0 & 0 & 0 & 0 & 0 & 1 \\
\hline 2 & 76.1 & $510.0 / 96.3 / 89$ & 6.70 & 1 & 0 & 0 & 0 & 0 & 1 \\
\hline 3 & 79.6 & $511.5 / 96.6 / 90$ & 6.43 & 1 & 0 & 0 & 0 & 1 & 1 \\
\hline 4 & 73.8 & $514.5 / 97.2 / 92$ & 6.97 & 0 & 0 & 1 & 1 & 1 & 1 \\
\hline 5 & 79.1 & $522.0 / 98.6 / 97$ & 6.60 & 1 & 1 & 1 & 0 & 1 & 1 \\
\hline 6 & 82.5 & $525.0 / 99.2 / 99$ & 6.36 & 1 & 1 & 1 & 1 & 1 & 1 \\
\hline
\end{tabular}

$*$ Kok $=$ Kokkola, Rov $=$ Rovamieni, Oulai $=$ Oulainen, Kaj $=$ Kajaani

Efficiency of different warehouse sites or their combinations are measured as delivered freight per transport time $\left(\mathrm{m}^{3} / \mathrm{h}\right)$. In the case of locating only one warehouse, delivery efficiency $\left(7.03 \mathrm{~m}^{3} / \mathrm{h}\right)$ and share of delivered freight (95.2\% of weekly demand) are at the optimal level when a warehouse is located in Oulu (Figure 2). This is mainly caused by the large delivery demand of the Oulu hospital and relatively dense demand within region surrounding the city of Oulu set the main focus of demand in the area. With two warehouses, a slightly greater share of freight $(96.3 \%)$ can be efficiently delivered, but the geographic coverage of the network is larger, which also impairs delivery efficiency $\left(6.70 \mathrm{~m}^{3} / \mathrm{h}\right)$. Thus, by increasing the amount of warehouses the coverage of the network may be slightly increased, but delivery efficiency cannot be significantly increased (Table 2). In other words, there is no potential to gain remarkable increases in delivery efficiency by increasing the number of warehouses in the area to higher than two. 


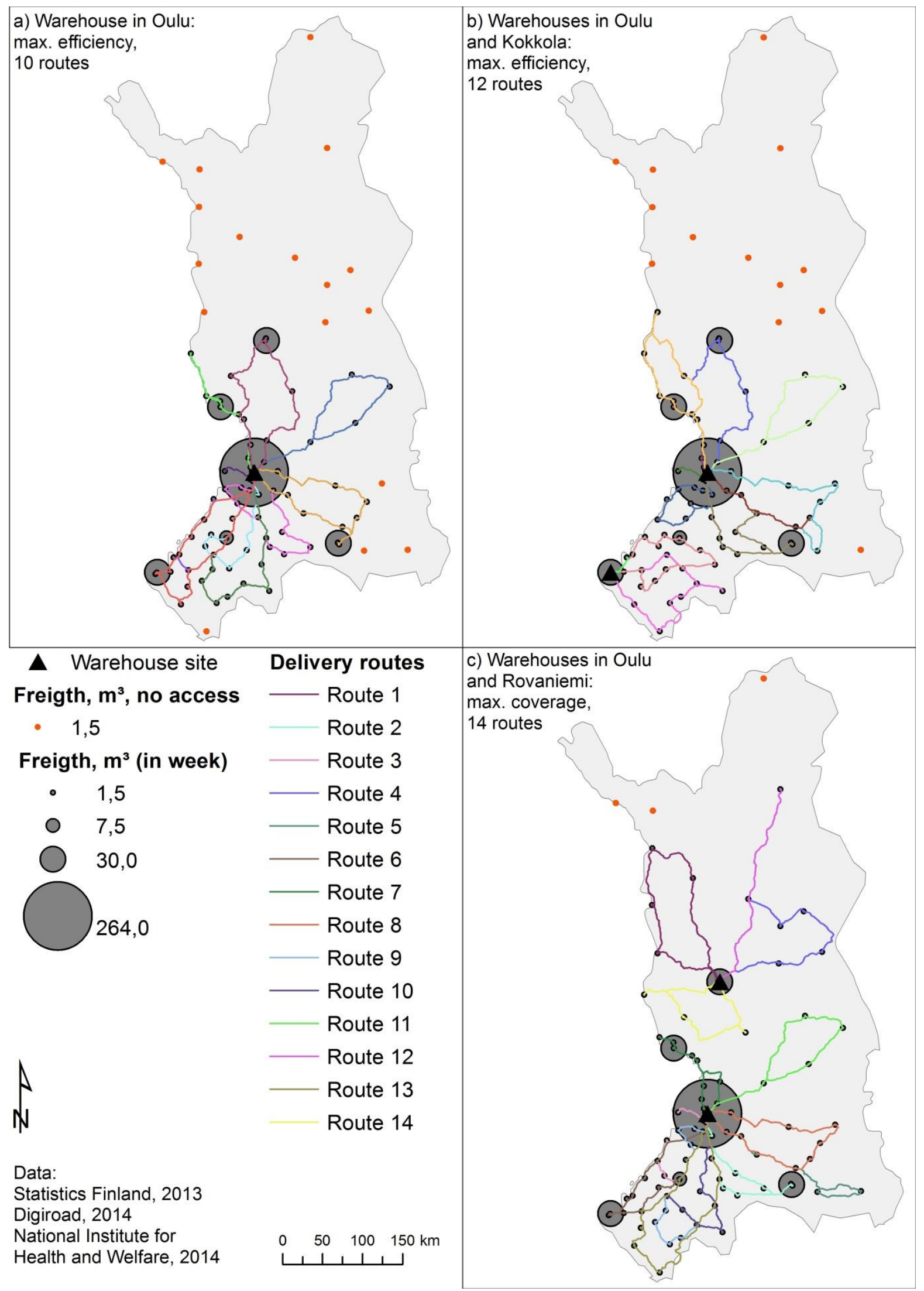

Figure 2. Geographic distribution of freight delivery demand and examples of delivery routes operable from a) the optimal site of one warehouse and b) optimal sites of two warehouses, when delivery efficiency is optimised and c) when coverage of the delivery network is optimised. 
Considering the efficiency of two or more warehouse sites is more complicated due to the higher number of combinations and the effect of the trade-off between delivery efficiency and the geographic reach of the delivery network. There are several different opportunities for locating warehouses almost as efficiently with respect to delivery accessibility, but also notable differences are found (Figure 3). Six options have better efficiency than $6.5 \mathrm{~m}^{3}$ delivered per hour and all these have a coverage of nodes including at least of $95 \%$ of freight delivery demand. The best realised efficiency is $7.03 \mathrm{~m}^{3} / \mathrm{h}$ and the worst is $3.01 \mathrm{~m}^{3} / \mathrm{h}$, and 17 options of 63 potential warehouse location settings may cover $99.2 \%$ of delivery demand.

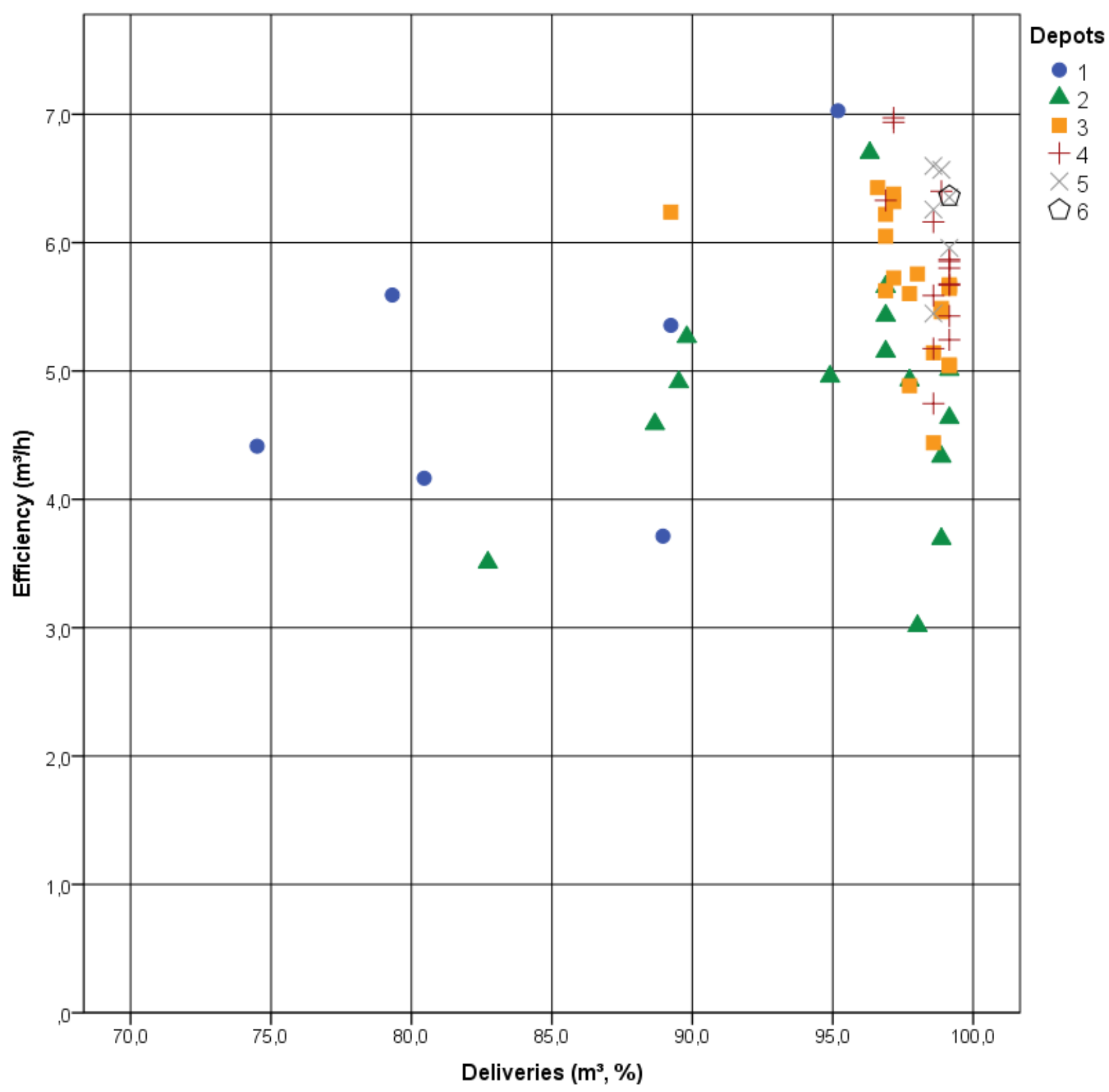

Figure 3. Route efficiency in relation to delivery network coverage.

If geographic coverage of the delivery network is considered as the key factor in allocating warehouse locations, the dispersed pattern is more beneficial (Table 3). When the amount of delivered freight is maximised instead of efficiency of deliveries within set constraints, delivery network efficiency may be increased slightly by increasing the amount of warehouses. The northernmost warehouse site in Rovaniemi (see Figure 1) is clearly an advantageous site for serving the most distant delivery demand in northern areas. 
Coverage of the delivery network could reach $99.2 \%$, by locating a second warehouse in Rovaniemi. In allocating one or two warehouses $95.2-99.2 \%$ of the delivery demand could be satisfied.

Table 3. Number of allocated warehouses and metrics related to delivery networks having the widest coverage.

\begin{tabular}{|c|c|c|c|c|c|c|c|c|c|}
\hline \multirow{2}{*}{$\begin{array}{c}\text { Warehouses } \\
n(\mathrm{~N})\end{array}$} & \multirow{2}{*}{$\begin{array}{l}\text { Cost } \\
H_{n}(\mathrm{~h})\end{array}$} & \multirow{2}{*}{$\begin{array}{c}\text { Deliveries } \\
V_{n}\left(m^{3} /(\%) / N\right)\end{array}$} & \multirow{2}{*}{$\begin{array}{c}\text { Efficiency } \\
E_{j}\left(m^{3} / h\right)\end{array}$} & \multicolumn{6}{|c|}{ Potential warehouse sites } \\
\hline & & & & Kok & Rov & Kemi & Oulai & Kaj & Oulu \\
\hline 1 & 71.7 & $504.0 / 95.2 / 85$ & 7.03 & 0 & 0 & 0 & 0 & 0 & 1 \\
\hline 2 & 104.8 & $525.0 / 99.2 / 99$ & 5.01 & 0 & 1 & 0 & 0 & 0 & 1 \\
\hline 3 & 92.6 & $525.0 / 99.2 / 99$ & 5.67 & 0 & 1 & 0 & 1 & 0 & 1 \\
\hline 4 & 89.5 & $525.0 / 99.2 / 99$ & 5.87 & 0 & 1 & 1 & 1 & 1 & 0 \\
\hline 5 & 82.6 & $525.0 / 99.2 / 99$ & 6.35 & 0 & 1 & 1 & 1 & 1 & 1 \\
\hline 6 & 82.5 & $525.0 / 99.2 / 99$ & 6.36 & 1 & 1 & 1 & 1 & 1 & 1 \\
\hline
\end{tabular}

$*$ Kok $=$ Kokkola, Rov $=$ Rovamieni, Oulai $=$ Oulainen, Kaj = Kajaani

Even though the minority of delivery demand $(0.8-4.8 \%)$ would then be left out of this delivery network, their logistics services could be arranged by customised or frugal solutions. All of these small health centres located in rural areas are characterized by the longest delivery distances and smallest quantities. As the interview data providing the background of this paper indicates, these locations could find reasonable solutions by using the existing transport networks of, for example, grocery stores and postal deliveries. Also, small amounts of goods could possibly be transported alongside non-urgent ambulance and taxi transport.

\section{Conclusive discussion}

This study allocates centralised warehousing functions for public health care facilities characterized by long delivery distances. Optimised delivery routes are applied to solve the facility allocation problem. The tradeoff between service level and geographic reach in the delivery network was controlled with constraints of delivery costs-efficiency and share of successful deliveries. Even in the most centralised versions of the delivery network scenarios, where driving time is the lowest ( 71.7 hours), at least $95.2 \%$ of the materials can be delivered. The key empirical outcome of this study shows that the sparsely distributed health care freight deliveries in North Finland could be efficiently served by one or two centralised warehouses. It is also a notable finding that increasing the number of warehouses has only a minimal effect on delivery network efficiency. Moreover, decreasing the number of warehouses results in lower inventory within the whole health service system (see Croxton \& Zinn, 2005).

Due to a trade-off between reach of the delivery network and efficiency of deliveries, warehousing functions of the most extremely distant health centres have a low potential to be reached effectively by centralised delivery network. Again, maximising only delivery efficiency without considering the extent of the delivery network would produce an extremely restricted outcome with a small volume. Maximising the extent would again, without considering efficiency, produce a very inefficient network. Thus, the analysis needs to be tailored to the larger logistics entity. In addition, service solutions for remainder deliveries $(3.7-4.8 \%)$ of units not assigned to the delivery network need to be considered carefully. Although the amount of demanded material is low, the need and the importance of the items to care processes are high. These remainders represent geographically large areas in the rural parts of the country with the longest transport distances. Instead of including these locations into a robust delivery network, finding customised and frugal solutions as consolidating material deliveries with personnel transports (bus, taxi, ambulance), postal delivery, grocery supply chain etc. could be beneficial.

Materials considered in this paper are mostly care items which can be delivered to health centres at the given frequencies (e.g. once a week in small health centres) and the logistics centre is mainly considered as a warehouse in this paper. However, in a broader sense the centre could be considered to include a wide range of material logistics services in healthcare including pharmacy, laboratory, instruments and equipment, food supply and laundry. In a more advanced view, an optimised delivery network would also be applied in flow 
for reverse logistics including such things as laundry and laboratory samples. Comparative cases in this paper offer these services to some extent. An even wider variety of services could be offered if a centre would consider itself as an expert organisation and service centre.

An essential role of the vehicle routing algorithm in locating warehouses is clear. The vehicle routing problem tool in ArcGIS (ESRI, 2012) is a functional method in delivery route generation. However, generating routes by a very exiguous or very ample fleet of delivery vehicles seems to set challenging conditions and exceptions in short distance routing need to be controlled. Thus, comparing different routing algorithms would be an interesting and necessary, but demanding, target for further analysis.

The GIS-based analyses of facility location and route planning offer several advantages. If conducted separately, these optimization tasks could be carried out with basic logistics planning tools, starting from relatively simple methods such as the gravity method for facility location and the sweep method or savings method for route planning (see e.g. Ballou, 2004: 235-253). However, by combined analysis, the accessibility problem can be approached more holistically to expose the trade-offs between the number and location of facilities and transportation costs under the assumed constraints such as vehicle capacities and driving times.

Findings of this study support the use of the GIS environment as an adjustable calculation framework to approach location-allocation and cost trade-off problemacy of service supply also in the case of warehouses. The analysis is suitable in optimising locational opportunities for centralising warehousing functions also in other contexts when coordinated delivery demand data are available. This study offers objective calculation of the plausible distribution system in the area, depending on whether an efficient or spatially extensive delivery network is preferred. The practitioners and the market possibilities will later form a suitable distribution strategy and operations to meet the desired targets.

Even though this study is not a definitive solution to the specific planning problem in health care logistics, it is the first attempt to look at the big picture of health care logistics within long distances by the case of Northern Finland. The study can help to reveal the potential for redesigning the logistics system through inventory centralisation and transport route optimisation. For health care logistics management, for instance, this kind of computational solution offers direct opportunities for utilizing competitive tendering in the acquisition of capacity and driving time-based transport services from external logistics providers. From a wider societal perspective, the study may contribute to the ability to cope with the growing cost pressures in health care, and at the same time serve in creating solutions supporting the maintenance of health care services also in sparsely populated rural regions.

\section{Acknowledgements}

This study is a part of the project "Effective, user-centred and scalable support service models in long distance health care systems". The project was funded by TEKES - "the Finnish Funding Agency for Innovation" with Northern Ostrobothnia Hospital District, Lapland Hospital District, City of Oulu and Posti Oy. We wish to thank warmly the representatives of these organisations and Nordic Health Group Oy for serving as an advisory board of the project and for fruitful and inspiring discussions. We would like to thank also our project partners in Oulu Business School and Industrial Engineering and Management for effective, stimulating and convenient cooperation throughout the project that improved this research significantly. Finally, we wish to thank two anonymous referees for valuable comments, Tiina Lankila and Tiina Huotari for scientific commentary as well as Harri Antikainen for GIS-methodological discussions.

\section{References}

Abdulsalam, Y., Gopalakrishnan, M., Maltz, A., \& Schneller, E. (2015). Health Care Matters: Supply Chains In and Of the Health Sector. Journal of Business Logistics, 36, 335-339.

Abrahamsson, M., Aldin, N., \& Stahre, F. (2003). Logistics platforms for improved strategic flexibility. International Journal of Logistics: Research and Applications, 6, 85-106.

Ahlqvist, T., Ahokangas, P., Atkova, I., Alasaarela, E., Bräysy, T., Caló, A., Haapala, A. ... (2014). Smarctic - A Roadmap to Smart Arctic Specialization. Project report. Oulu: Thule Institute, University of Oulu. 
Baldacci, R., Toth, P., \& Vigo, D. (2010). Exact algorithms for routing problems under vehicle capacity constraints. Annals of Operations Research, 175, 213-245.

Ballou, R. H. (2004). Business Logistics. Supply Chain Management. Planning, Organizing and Controlling the Supply Chain. (5th ed.). London: Prentice Hall.

Becker, J., Görke, M., Felix, C., \& Schmidt, M. (2016). Model-based potential analysis of the distribution logistics: a case study. Production Planning \& Control, 27, 698-707.

Beier, F. J. (1995). The management of the supply chain for hospital pharmacies: a focus on inventory management practices. Journal of Business Logistics, 16.

Bosona, T. G., \& Gebresenbet, G. (2011). Cluster building and logistics network integration of local food supply chain. Biosystems Engineering, 108, 293-302.

Bozkaya, B., Yanik, S., \& Balcisoy, S. (2010). A GIS-based optimization framework for competitive multifacility location-routing problem. Networks and Spatial Economics, 10, 297-320.

Brahimi, N., \& Khan, S. A. (2014). Warehouse location with production, inventory, and distribution decisions: a case study in the lube oil industry. 4OR, 12, 175-197.

Campbell, J. F., \& O'Kelly, M. E. (2012). Twenty-five years of hub location research. Transportation Science, 46, 153-169.

Christopher, M. (1998). Logistics and Supply Chain Management - Strategies for Reducing Cost and Improving Service. London: Prentice Hall.

Coffee, N., Turner, D., Clark, R. A., Eckert, K., Coombe, D., Hugo, G., Van Gaans, D., Wilkinson, D. Stewart, S., \& Tonkin, A. A. (2012). Measuring national accessibility to cardiac services using geographic information systems. Applied Geography, 34, 445-455.

Crainic, T. G., \& Laporte, G. (1997). Planning models for freight transportation. European Journal of Operational Research, 97, 409-438.

Cromley, E. K., \& McLafferty, S. L. (2011). GIS and public health. New York: Guilford Press.

Croxton, K. L., \& Zinn, W. (2005). Inventory considerations in network design. Journal of Business Logistics, 26, 149-168.

de Vries, J., \& Huijsman, R. (2011). Supply chain management in health services: an overview. Supply Chain Management: An International Journal, 16, 159-165.

ESRI. Algorithms used by Network Analyst. (2012). http://help.arcgis.com/en/arcgisdesktop/10.0/help/index.html\#//004700000053000000 Accessed 10.10. 16.

Farahani, R. Z., Hekmatfar, M., Arabani, A. B., \& Nikbakhsh, E. (2013). Hub location problems: A review of models, classification, solution techniques, and applications. Computers \& Industrial Engineering, 64, 1096-1109.

[dataset] Finnish Transport Agency. (2014). Digiroad, National Road and Street Database.

Gebresenbet, G., Nordmark, I., Bosona, T., \& Ljungberg, D. (2011). Potential for optimised food deliveries in and around Uppsala city, Sweden. Journal of Transport Geography, 19, 1456-1464.

Geoffrion, A. M., \& Powers, R. F. (1995). Twenty Years of Strategic Distribution System Design: An Evolutionary Perspective. Interfaces, 25, 105-127.

Graves, S. C., Willems, S. P., \& Zipkin, P. (2000). Optimizing Strategic Safety Stock Placement in Supply Chains. Manufacturing \& Service Operations Management, 2, 68-83.

Handfield, R. B., \& Nichols, E. L. (1999). Introduction to supply chain management (Vol. 183). Upper Saddle River, NJ: prentice Hall.

Harrison, A., \& van Hoek, R. (2005). Logistics Management and Strategy. Harlow: Pearson Education Limited.

Heizer, J., \& Render, B. (2014). Operations Management: Sustainability and Supply Chain Management. Harlow: Pearson Education Limited. 
Hesse, M., \& Rodrigue, J. P. (2004). The transport geography of logistics and freight distribution. Journal of transport geography, 12, 171-184.

Jarrett, G. P. (1998). Logistics in the Health Care Industry. International Journal of Physical Distribution \& Logistics Management, 28, 741-772.

Kaplan, R. S., \& Porter M. E. (2011). How to solve the cost crisis in health care. Harvard Business Review, 89, 46-52.

Klose, A., \& Drexl, A. (2005). Facility location models for distribution system design. European Journal of Operational Research, 162, 4-29.

Kohn, C., \& Brodin, M. H. (2008). Centralised distribution systems and the environment: how increased transport work can decrease the environmental impact of logistics. International Journal of Logistics: Research and Applications, 11, 229-245.

Kotavaara, O., Antikainen, H., \& Rusanen, J. (2011). Population change and accessibility by road and rail networks: GIS and statistical approach to Finland 1970-2007. Journal of Transport Geography, 19, 926-935.

Kotavaara, O., Hakkarainen, T., Huotari, T., Keistinen, T., \& Rusanen, J. (2015). Mapping Opportunities for Enhancing Effective-ness of Health Care System by GIS Based Accessibility Analyses: Locating Core and Support Services within Long Distances in Northern Finland. In: G. Gartner, \& H. Huang (Eds), Proceedings of the 1st ICA European Symposium on Cartography (pp. 76-91).Vienna: EuroCarto.

Kumar, A., Ozdamar, L., \& Ning Zhang, C. (2008). Supply chain redesign in the healthcare industry of Singapore. Supply Chain Management: An International Journal, 13, 95-103.

Landry, S., \& Philippe, R. (2004). How logistics can service healthcare. Supply Chain Forum: An International Journal, 5, 24-30.

Lei, T. L., Church, R. L., \& Lei, Z. (2016). A unified approach for location-allocation analysis: integrating GIS, distributed computing and spatial optimization. International Journal of Geographical Information Science, 30, 515-534.

Luo, J. (2014). Integrating the Huff Model and Floating Catchment Area Methods to Analyze Spatial Access to Healthcare Services. Transactions in GIS, 18, 436-448.

McGrail, M. R., \& Humphreys, J. S. (2014). Measuring spatial accessibility to primary health care services: Utilising dynamic catchment sizes. Applied Geography, 54, 182-188.

Melo, MT., Nickel, S., \& Saldanha-Da-Gama, F. (2009). Facility location and supply chain management - A review. European Journal of Operational Research, 196, 401-412.

Mestre A. M., Oliveira, M. D., \& Barbosa-Póvoa, A. P. (2015). Location-allocation approaches for hospital network planning under uncertainty. European Journal of Operational Research, 240, 791-806.

Miller H., \& Shaw S.-L., (2001). Geographic Information Systems for Transportation Principles and Application. Oxford: Oxford University Press

Nagy, G., \& Salhi, S., (2007). Location-routing: Issues, models and methods. European Journal of Operational Research, 177, 649-672.

Olsson, O., Wiger, M., \& Aronsson, H. (2014). Developments in the Field of Healthcare Logistics and SCM: A Patient Flow Focus. 26th Conference of the Nordic Logistics Research Network. Copenhagen: Copenhagen Business School.

Páez, A., Scott, D. M., \& Morency, C. (2012). Measuring accessibility: positive and normative implementations of various accessibility indicators. Journal of Transport Geography, 25, 141-153.

Pohjosenperä, T., Kotavaara, O., Rusanen, J., \& Juga, J. (2016). Accessibility of Material Logistics Services in Healthcare. 28th Conference of the Nordic Logistics Research Network. Turku: University of Turku.

Polo, G., Acosta, C. M., Ferreira, F., \& Dias, R. A. (2015). Location-allocation and accessibility models for improving the spatial planning of public health services. PloS one, 10.

Poulin, E. (2003). Benchmarking the Hospital Logistics Process: A Potential Cure for the Ailing Healthcare Sector. CMA Management, 77, 20-23. 
Prodhon, C., \& Prins, C. (2014). A survey of recent research on location-routing problems. European Journal of Operational Research, 238, 1-17.

Rodrigue J-P, Comtois, C., \& Slack, B. (2013). The Geography of Transport Systems. (3th ed.). New York: Routledge.

Rodrigue, J. P. (2006). Transport geography should follow the freight. Journal of Transport Geography, 14, 386-388.

Tenkanen, H., Saarsalmi, P., Järv, O., Salonen, M., \& Toivonen, T. (2016). Health research needs more comprehensive accessibility measures: integrating time and transport modes from open data. International Journal of Health Geographics, 15.

Tong, D., \& Murray, A. T. (2012). Spatial optimization in geography. Annals of the Association of American Geographers, 102, 1290-1309.

Vissers, J., \& Beech, R. (2005). Health operations management: patient flow logistics in health care. New York: Routledge.

Yiannakoulias, N., Bland, W., \& Svenson, L. W. (2013). Estimating the effect of turn penalties and traffic congestion on measuring spatial accessibility to primary health care. Applied Geography, 39, 172-182.

Zhang, M., \& Pel, A. J. (2016). Synchromodal hinterland freight transport: Model study for the port of Rotterdam. Journal of Transport Geography, 52, 1-10. 